This item was submitted to Loughborough's Research Repository by the author.

Items in Figshare are protected by copyright, with all rights reserved, unless otherwise indicated.

\title{
How valid and accurate are measurements of golf impact parameters obtained using commercially available radar and stereoscopic optical launch monitors?
}

\section{PLEASE CITE THE PUBLISHED VERSION}

https://doi.org/10.1016/j.measurement.2017.08.009

\section{PUBLISHER}

(C) Elsevier

\section{VERSION}

AM (Accepted Manuscript)

\section{PUBLISHER STATEMENT}

This work is made available according to the conditions of the Creative Commons Attribution-NonCommercialNoDerivatives 4.0 International (CC BY-NC-ND 4.0) licence. Full details of this licence are available at: https://creativecommons.org/licenses/by-nc-nd/4.0/

\section{LICENCE}

CC BY-NC-ND 4.0

\section{REPOSITORY RECORD}

Leach, Robert J., Steph Forrester, Aimee Mears, and Jonathan Roberts. 2017. "How Valid and Accurate Are Measurements of Golf Impact Parameters Obtained Using Commercially Available Radar and Stereoscopic Optical Launch Monitors?". Loughborough University. https://hdl.handle.net/2134/26658. 


\title{
How valid and accurate are measurements of golf impact parameters obtained using commercially available radar and stereoscopic optical launch monitors?
}

\author{
R. J. Leach, S. E. Forrester, A. C. Mears, J. R. Roberts. \\ Sports Technology Institute, Wolfson School of Mechanical, Electrical and Manufacturing Engineering, Loughbor- \\ ough University, Loughborough, Leicestershire, UK
}

\begin{abstract}
The application of measurement technology in golf is increasing. In particular, measures of golf performance are valuable to coaches, golfers, club-fitters and equipment manufacturers. Commercially available launch monitors, such as the TrackMan Pro IIIe and Foresight GC2+HMT, offer bespoke instantaneous methods to measure such parameters. Uncertainty in the outputs, however, is not well established nor independently verified. This study aimed to determine the degree of agreement between parameters from two launch monitors with measurements taken using a benchmark system. A total of 240 shots were collected with a driver, 7 -iron and utility wedge. Shots were simultaneously tracked by each system and outputs compared using Limits of Agreement analysis. In addition, two reference grades were defined based on different levels of agreement; research and coaching grade. Agreement between the launch monitors and the benchmark system was noticeably stronger for ball parameters with greater variability in clubhead parameters. Furthermore, for both launch monitors, the strength of agreement for several parameters varied between clubs. The majority of ball parameters from both launch monitors fell within the research reference grade, but caution is needed for the use of clubhead parameters within a research environment. For coaches and clubfitters, the results suggest the launch monitor parameters are largely of sufficient quality.
\end{abstract}

\section{Introduction}

The application of measurement science in golf is increasing, with the development of new technologies to measure clubhead-ball impacts. Measurement of the impact parameters during a golf swing is of interest because ultimately, they determine the outcome of a shot. During biomechanical investigation of a golfer's swing these parameters are often used as the performance outcome measures [1-2] and, typically, they are measured either using launch monitors or motion analysis systems [3-5]. Motion analysis systems are usually configured for biomechanical analysis, consequently the clubhead and ball are often tracked via a single marker on each and data collection frequency is often too low to ensure a measurement is taken at the point of impact. Launch monitor technologies represent a bespoke instantaneous solution; however, the measurement uncertainty of such devices is not well established.

Two examples of commonly used launch monitors are TrackMan Pro IIIe (TrackMan A/S, Denmark, cost $\sim 16 \mathrm{k}$ dollars U.S.) and Foresight GC2+HMT (Foresight Sports, San Diego, CA, cost $\sim$ rok dollars U.S.). The former is positioned behind the golfer, pointing along the target line and uses Doppler radar technology to determine the motion path of the clubhead and ball. Parameters related to the changing orientation of the clubhead are more diffi- cult to measure directly with this technology and these parameters are calculated from impact algorithms using data that has been measured. Foresight is a stereoscopic optical system, positioned perpendicular to the target line, and all reported impact parameters are directly measured from images taken immediately pre- and postimpact. There is no formal procedure for aligning the Foresight unit relative to the target line, raising questions over parameters related to the path and orientation of the clubhead and ball relative to the target line. Furthermore, although the ball needs no altering, markers are required to track the clubhead. Both manufacturers state the accuracy of their systems in their technical specifications, however, the origin of these values is unclear and, to date, they have not been independently verified. Given the need for accurate performance outcomes it is important to validate such systems. One approach that can be taken is to compare the outputs against measurements from a system with known uncertainty.

GOM Inspect (GOM mbH, Germany) is an optical ${ }_{3} \mathrm{D}$ dynamic displacement measurement system [6]. The accuracy of the system is dependent on the setup, including the camera, lens, calibration, lighting and marker quality; however, through personal communication, the manufacturer suggested, as a general rule, the system is accurate to 25 microns per metre field of view. The hardware con- 
sists of multiple high-speed video cameras, allowing dynamic events to be investigated at high frame rates and in three dimensions. Although developed for aeronautical and automotive industries, the potential of the system for tracking a driver clubhead has been demonstrated by Ellis et al. [7]. This previous study did not include ball tracking and was limited by the definition of the clubface plane, which was defined by three markers on the face and, therefore, did not fully account for the curvature of a driver clubface.

The purpose of this study was to determine the degree of agreement, both systematic and random, between the two commercial launch monitors, TrackMan Pro IIIe and Foresight GC2+HMT, and the benchmark system, GOM Inspect. As a precursor to this main purpose, it was necessary to assess the accuracy of the GOM system for this specific application. It was hypothesised that the launch monitors would show close agreement to the GOM system for clubhead and ball velocities and trajectories but poorer agreement for clubhead orientations and ball spinrate.

\section{Methods}

The underlying principle of the launch monitor validation was to evaluate the launch monitors in a manner representative of how they would be used in practice: 1 . The two launch monitors were in daily use in research and development laboratories and had not been specially selected or configured for the testing; 2. Manufacturers' guidance was followed in their setup; 3. No non-standard or specialist items, that were not widely available to the general public, were employed to optimise their performance; and 4. Measurements were taken from actual golf shots using all three systems simultaneously to allow direct comparison of results from each shot.

\section{Participants}

Ethical approval was gained from the University's Ethics Committee and all participants provided voluntary informed consent. Eight right-handed golfers (age $26 \pm 7$ years; height $1.82 \pm 0.07 \mathrm{~m}$; mass $78 \pm 12 \mathrm{~kg}$; experience 10 \pm 7 years) volunteered for the study. Golfer handicaps ranged from zero to recreational (no official handicap).

\section{Equipment set-up \& alignment}

A plan view of the laboratory setup is shown in Figure 1. For the GOM system, four Photron Fastcam SA1.1 (Photron, San Diego, CA) high speed video cameras $(5400 \mathrm{~Hz}$; $1 / 50000 \mathrm{sec}$ ), each fitted with a Titanar $50 \mathrm{~mm}$ fixed focal length lens, were placed approximately side on to the hitting mat to capture each shot through impact. Additional flicker-free lighting focused on the tee. The cameras operated as two pairs, one tracking the clubhead, the other the ball. The exact setup was guided by GOM recommendations; the ball camera pair sat at ground level and the clubhead camera pair on a tripod, tilted $45^{\circ}$ down towards the tee (Figure 2). The set-up was designed for capture volumes around the tee of approximately $300 \times 300 \times 300$ $\mathrm{mm}$.

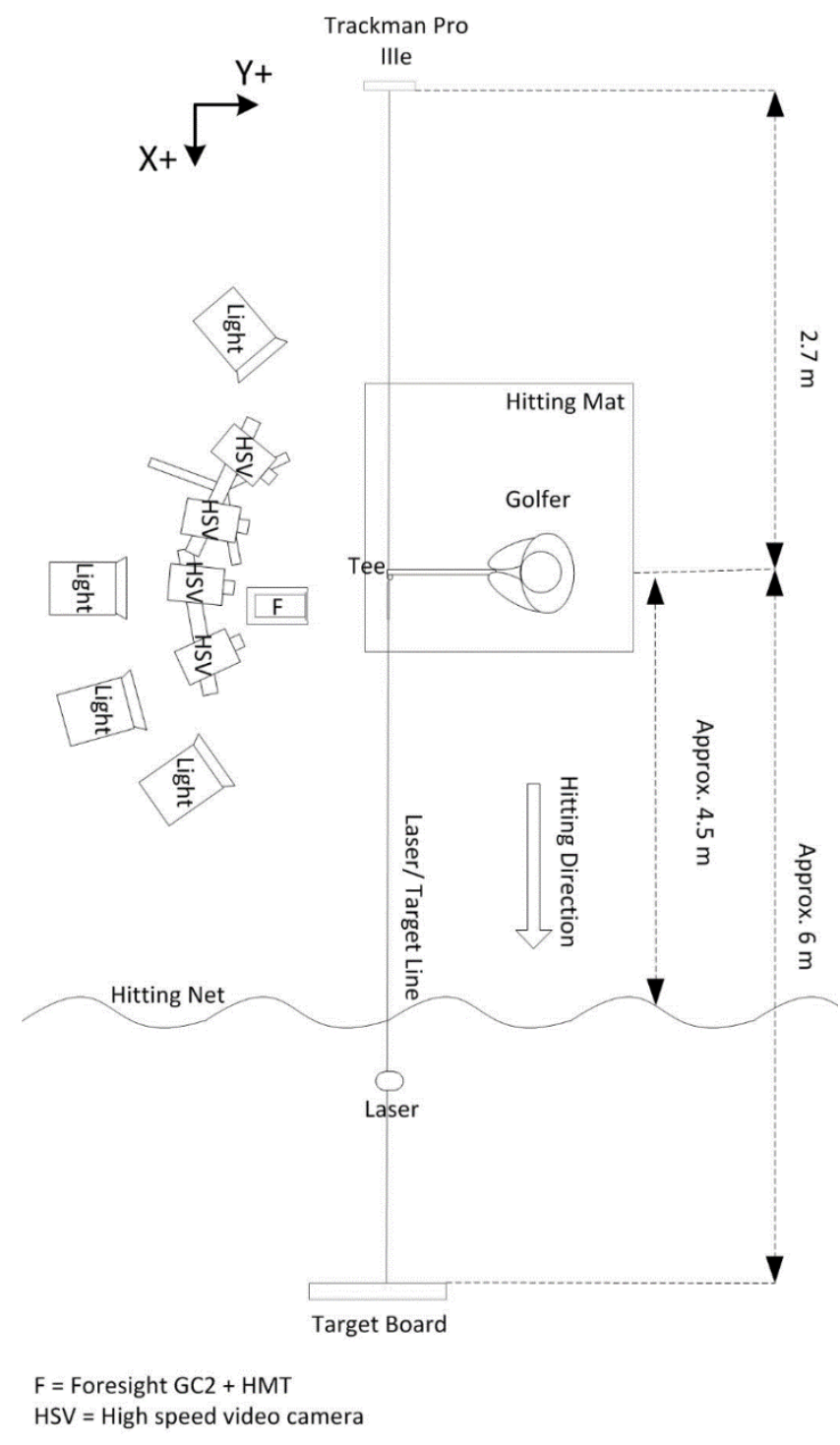

Figure 1: Plan view of the laboratory setup

The measurement volumes were independently calibrated in accordance with the manufacturer's instructions by imaging a specific calibration artefact, supplied with the GOM system, in multiple positions and orientations within the capture volume. The calibration artefact was certified by a calibration laboratory that was accredited within the International Laboratory Accreditation Corporation; therefore, traceable to national measurement standards maintained by the National Metrology Institute of Germany (Physikalisch-Technische Bundesantalt). A calibration deviation of $\leq 0.03$ pixels was achieved for each calibration; a value equating to less than nine microns in the capture volume.

The GOM calibration procedure generated a local coordinate system (LCS) for each camera pair; a subsequent transformation was required to align each camera pair with a common global coordinate system (GCS). This was achieved through development of a rig consisting primarily of two perpendicular arms (target line and perpendicular), supported on adjustable feet (Figure 3). 
a)

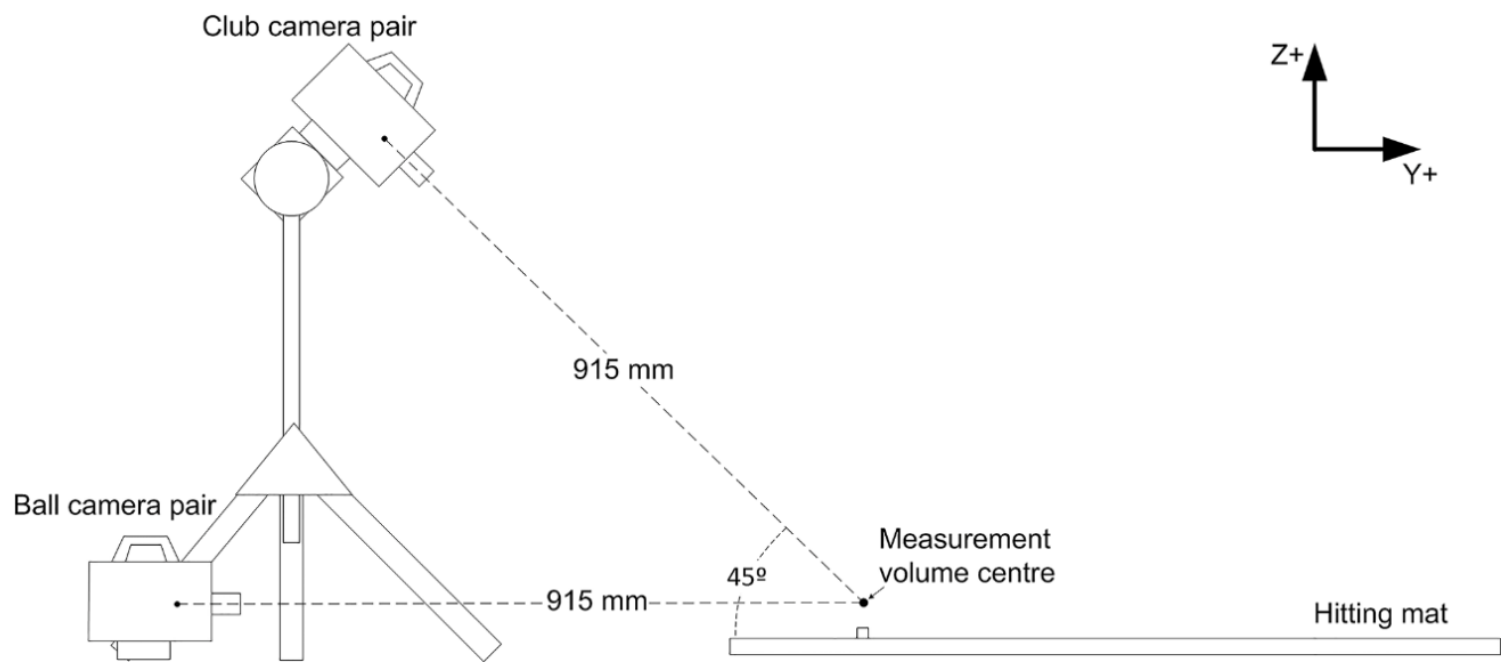

b)

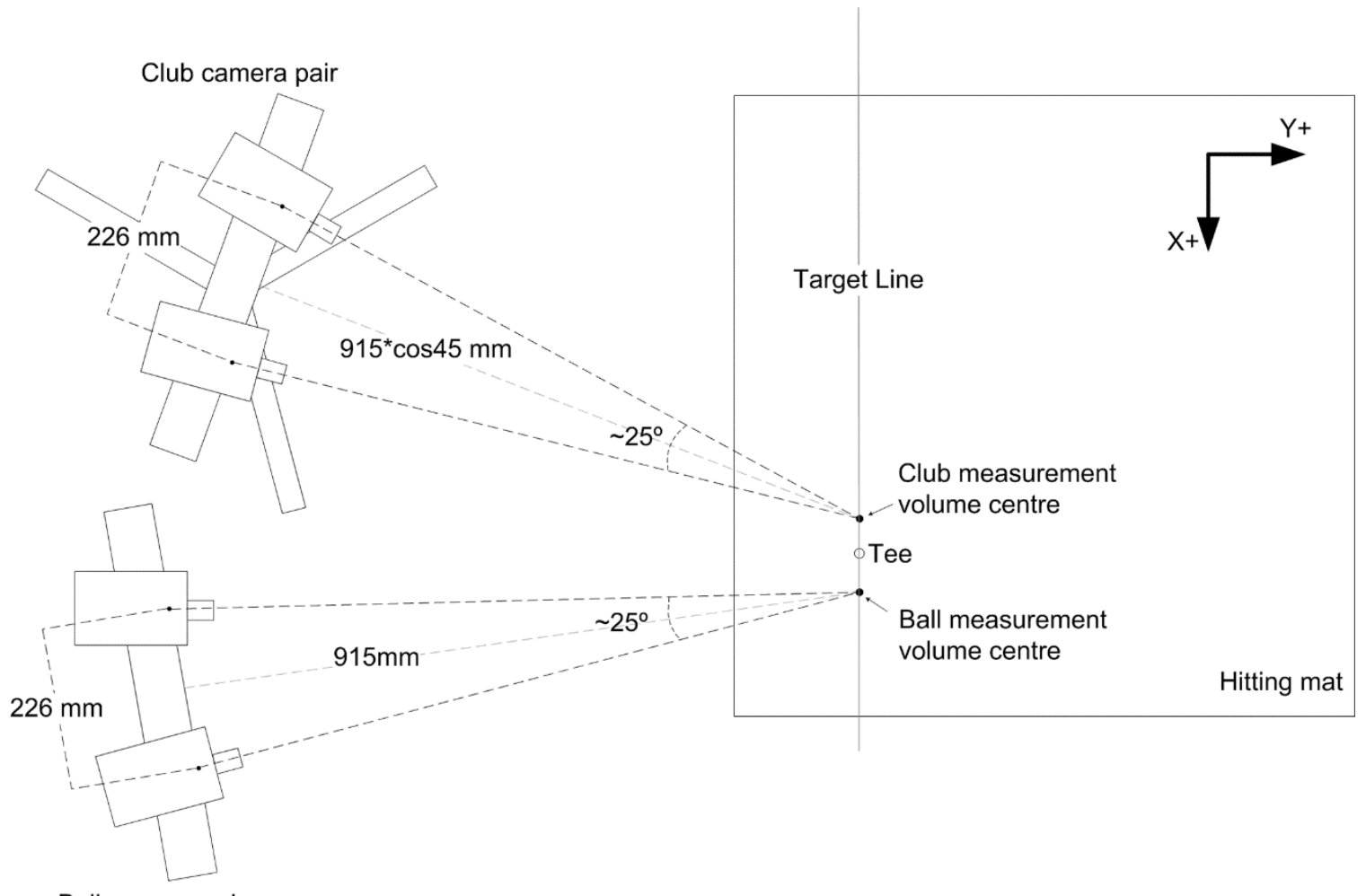

Ball camera pair

Figure 2: Camera setup viewed from $a$ ) the hitting net and $b$ ) above

The $3 \mathrm{D}$ positions of randomly spaced, $5 \mathrm{~mm}$ diameter markers that covered the rig were measured using the GOM 3D optical coordinate measurement software (TRITOP V6.3). The software was used to create the following three best-fit orthogonal planes, intersecting at an origin subsequently forming the GCS (Figures $2-3$ ).

The GOM calibration procedure generated a local coordinate system (LCS) for each camera pair; a subsequent transformation was required to align each camera pair with a common global coordinate system (GCS). This was achieved through development of a rig consisting pri- marily of two perpendicular arms (target line and perpendicular), supported on adjustable feet (Figure 3). The $3 \mathrm{D}$ positions of randomly spaced, $5 \mathrm{~mm}$ diameter markers that covered the rig were measured using the GOM ${ }_{3} \mathrm{D}$ optical coordinate measurement software (TRITOP V6.3). The software was used to create the following three bestfit orthogonal planes, intersecting at an origin subsequently forming the GCS (Figures $2-3$ ).

- $\quad \mathrm{XY}-\mathrm{a}$ horizontal plane through all of the markers on the upper surface of the two arms of the rig. 
- $\quad \mathrm{XZ}$ - a vertical plane, perpendicular to XY, passing through the points on the vertical face of the target line arm.

- $\quad$ YZ - a vertical plane, perpendicular to $\mathrm{XY}$ and $\mathrm{XZ}$, passing through the points on the vertical face of the perpendicular arm.

A target line was defined using a vertical plane of laser light that passed through the tee projected from a selflevelling Leica Lino L36o (Figure 1). The rig was carefully positioned such that the target line arm was aligned with the laser beam and the legs adjusted so that the arms formed a horizontal plane as determined using a spirit level. Images of the rig in this position were captured with each camera pair. The TRITOP model of the rig was then fitted to the markers in view of the cameras. The LCS of each camera pair was independently transformed to align with the GCS defined by the rig.

Extensions to the rig were secured to align the TrackMan and Foresight units (Figure 3). Set-up of the units followed each manufacturer's guidelines [8-9]. The front face of the TrackMan unit was aligned perpendicularly to the target arm of the rig such that the laser beam bisected the vertical line in the ' $\mathrm{k}$ ' of the TrackMan logo, a distance of $2.7 \mathrm{~m}$ behind the tee. Final alignment was performed using the TrackMan Performance Studio 3.2 (TPS 3.2) software; the laser beam was visible to a built-in camera and was selected as the target line in the software. Other than a built-in accelerometer for self-levelling, Foresight has no formal alignment procedure, only that the ball must sit within the hitting zone when on the tee. Set up via the alignment rig ensured the front edge of the Foresight unit was parallel to the target arm of the rig. Once the launch monitors were setup and the rig had been imaged the rig was carefully removed from the hitting area.

\section{Club and ball preparation}

Three PING clubs were used: G25 Driver, K15 7-Iron and K15 utility wedge (Figure 4). Markers of $3 \mathrm{~mm}$ diameter covered the top and toe edges of the 7-Iron and utility wedge and five mm diameter markers covered the top surface of the driver. Markers unique to Foresight were placed on each clubface (Figure 5) according to the manufacturer's instructions for the HMT unit to track the clubhead [10].

Srixon Z-Star golf balls, sandblasted to minimise glare issues from the lights affecting GOM image quality, were used throughout the testing (Figure 6). Three mm diameter black markers were randomly placed in the dimples of each test ball. A metallic dot supplied by TrackMan was placed on the ball to enhance the radar signature, as recommended by the manufacturer to improve spin rate tracking. If TrackMan is not confident in this measurement it provides a calculated value; these values were excluded from the study.

All three clubheads and the ball were scanned using a GOM scanner (ATOS Core) and the associated software was used to create a surface mesh of each. The markers on the surface were also identified during each scan.

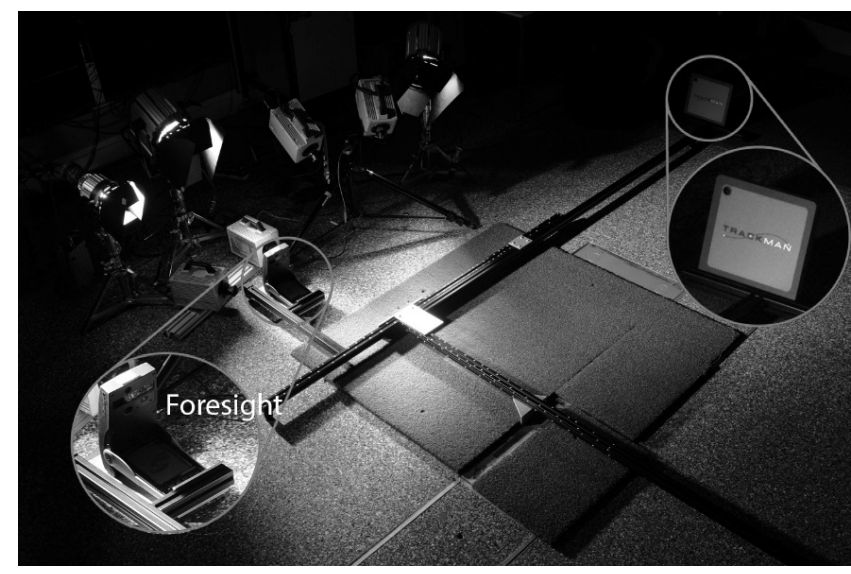

Figure 3: The rig used to define the GCS for the GOM system and to align all three measurement systems a)

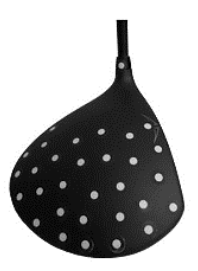

c)

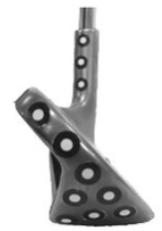

))
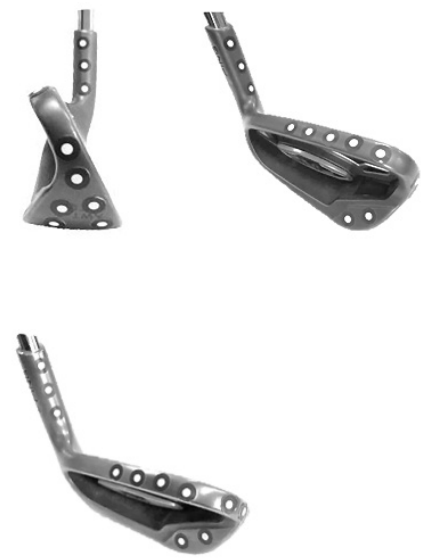

Figure 4: GOM marker placement on a) the driver; b) the 7Iron; c) the utility wedge

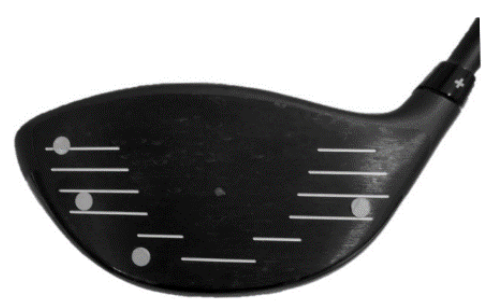

Figure 5: Foresight HMT markers placed on the driver clubface

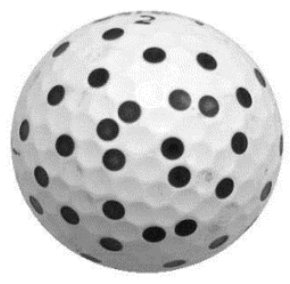

Figure 6: The golf ball covered in GOM markers 


\section{Data collection}

Participants conducted a self-guided warm-up, using separate clubs and balls until they felt comfortable to commence testing. Ten shots were then hit with each club with adequate rest between. All shots were included in the analysis regardless of impact location or shot outcome.

\section{Analysis of club \& ball data}

The clubhead and ball data were processed separately in GOM software (Inspect Professional V8) and MATLAB (The Mathworks, Natick, MA). To estimate the ball radius a sphere was fitted to the ball mesh giving a value of 21.3 mm (Inspect Professional V8). For each shot, the ball markers were reconstructed in the GCS and the virtual centre of the ball determined from a best-fit sphere of radius $21.3 \mathrm{~mm}$ fitted to the surface markers (Inspect Professional V8). The $3 \mathrm{D}$ coordinates of the sphere centre and tracked points were exported and a MATLAB script written to compute the ball parameters listed in Table 1. The parameters are given in the units provided by the launch monitor manufacturers rather than in SI units. Total spin rate was calculated from the point data. Rotation matrices from frame-to-frame were computed [11-12] and differentiated using the finite difference method [13].

Centre of gravity (COG) locations for each clubhead were provided by the manufacturer and a virtual marker created at this point from the clubhead mesh (Inspect Professional V8). Each clubhead mesh was fitted to the tracked points using the points on the clubhead identified during the scanning process. The ${ }_{3} \mathrm{D}$ coordinates of the COG were exported. Impact location was calculated by projecting the position of the centre of the ball onto the clubface of the mesh at the frame of first ball contact, providing a normal to the mesh. A MATLAB script calculated the clubhead parameters listed in Table 1, again based on the units provided by the launch monitor manufacturers.

The definitions of face angle and dynamic loft appeared to differ between the two launch monitors and so two measures of face angle and dynamic loft were calculated from the GOM data. The first was used for comparison with the TrackMan data and involved the angle between the impact location normal and the XZ plane for face angle and the XY plane for dynamic loft. For the second measure, used for comparison to the Foresight data, the normal was based upon the geometric centre of the club face (horizontally at the mid-point of the face grooves and vertically level with the centre groove or between the two centre grooves depending on the club) whilst the remainder of the definitions followed those of TrackMan.

The impact parameters from TrackMan and Foresight were automatically recorded by the systems and were exported to MATLAB for analysis. The data was collected in January 2015, using the latest software and firmware. Foresight measured all nine of the impact parameters calculated from the GOM system measurements while TrackMan measured seven; the exceptions being face angle and dynamic loft, which were calculated from other parameters.

\section{GOM system accuracy}

The GOM system is based on point tracking and the accuracy of this was assessed through a separate experiment where GOM measurements were compared to an independent system of known accuracy. A GOM calibration object was imaged in 50 random orientations from which the distances between nine pairs of points were calculated using the same methods as applied to the ball and clubhead tracking (Figure 7). The distances between the same nine pairs of points were measured independently using a SmartScope Flash 200 (OPG, Rochester, NY) multi-sensor measuring system with a given accuracy of 2.5-3.0 $\mu \mathrm{m}$ for measuring lengths in the range $10-100 \mathrm{~mm}$. The difference between the GOM and SmartScope measurements for each pair of points was determined from which the mean difference, representing the systematic error in GOM point tracking, and the $95 \%$ confidence intervals, representing the uncertainty due to random effects, were calculated. To confirm the applicability of this uncertainty value to the current study, the variability in ball centre position when stationary on the tee was also calculated from 120 trials across 3 golfers.

To estimate the uncertainty in the angle and velocity measures derived from the point data, a synthetic point data set representing the initial flight of the ball for a given launch angle, launch direction, linear ball velocity and spin rate was mathematically generated. Based on this data set, multiple simulations $(10,000)$ were run where Gaussian white noise was added to the point data to represent random effects on a measurement. The changes in launch angle, launch direction, linear ball velocity and spin rate caused by the introduction of noise to the data were calculated for each simulation, and from the overall distribution of these values, $95 \%$ confidence intervals were determined to represent the uncertainty in these parameter values when measured using the GOM system.

To support the outcomes of these simulations, the spin rate uncertainty was also measured experimentally using a custom-built sphere spinning device (Figure 8). A sphere manufactured to the same diameter as the golf ball and covered in GOM markers was securely attached on the motor shaft of the device. Three repetitions of 14 spin rates from nominally 3000-9500 rpm in $500 \mathrm{rpm}$ steps were performed. Images were recorded and processed using the same methods as applied to the ball tracking and these values were compared to spin rates measured directly from the device. For the latter, a reflective strip attached to the shaft generated a voltage pulse from an optical sensor once every revolution, which was captured using an oscilloscope triggered at the same time as the high speed cameras; spin rate was determined from the resulting waveform. Again, the $95 \%$ confidence intervals in the difference data between the GOM and oscilloscope spin rates were determined to represent the uncertainty in the GOM measurement of spin rate. 
Table 1: Definition of impact parameters compared in this study

\begin{tabular}{|c|c|c|c|c|c|c|c|}
\hline & Parameter & Unit $^{5}$ & Definition & TrackMan definition and stated accuracy [14] & & Foresight definition and stated accuracy & \\
\hline \multirow{4}{*}{ 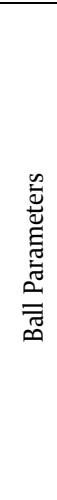 } & Ball velocity ${ }^{1}$ & $\mathrm{mph}$ & $\begin{array}{l}\text { Rate of change in position of the centre of a sphere fitted to } \\
\text { the ball markers. }\end{array}$ & $\begin{array}{l}\text { The speed of the golf ball's centre of gravity imme- } \\
\text { diately after separation from the club face. }\end{array}$ & \pm 0.1 & $\begin{array}{l}\text { The measurement of the golf ball's veloci- } \\
\text { ty measured just after impact. }\end{array}$ & \pm 0.5 \\
\hline & Launch Angle ${ }^{1}$ & $\underline{0}$ & $\begin{array}{l}\text { Angle formed between a line of best fit through the coordi- } \\
\text { nates of the ball centre and the XY plane in the direction of } \\
\text { the ball flight. }\end{array}$ & $\begin{array}{l}\text { The vertical angle relative to the horizon of the golf } \\
\text { ball's centre of gravity movement immediately after } \\
\text { leaving the club face. }\end{array}$ & \pm 0.2 & $\begin{array}{l}\text { The initial vertical angle of ascent [of the } \\
\text { ball] relative to the ground plane. }\end{array}$ & \pm 0.2 \\
\hline & Launch Direction ${ }^{1}$ & $\underline{0}$ & $\begin{array}{l}\text { Angle formed between a line of best fit through the XY coor- } \\
\text { dinates of the ball centre and the XZ plane, therefore repre- } \\
\text { senting a projected angle onto the XY plane. A positive value } \\
\text { meant a launch direction right of target. }\end{array}$ & $\begin{array}{l}\text { The initial direction of the ball relative to target } \\
\text { line. }\end{array}$ & - & $\begin{array}{l}\text { The initial horizontal angle [of the ball] } \\
\text { relative to the target line. }\end{array}$ & \pm 1.0 \\
\hline & Total Spin Rate ${ }^{1}$ & $\mathrm{rpm}$ & $\begin{array}{l}\text { Total angular velocity of the ball, calculated from the } 3 \mathrm{D} \\
\text { positions of the markers of the ball surface using the finite } \\
\text { differences method (Robertson, et al 2013). }\end{array}$ & $\begin{array}{l}\text { The rate of rotation of the golf ball around the } \\
\text { resulting rotational axis of the golf ball immediately } \\
\text { after the golf ball separates from the club face. }\end{array}$ & \pm 15 & $\begin{array}{l}\text { The total amount of spin around the tilt } \\
\text { axis (the axis the golf ball rotates } \\
\text { around). }\end{array}$ & \pm 50 \\
\hline \multirow{6}{*}{ 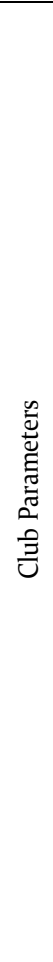 } & Clubhead Velocity ${ }^{2}$ & $\mathrm{mph}$ & Rate of change in position of the COG of the clubhead. & $\begin{array}{l}\text { The linear speed of the clubhead's centre of gravity } \\
\text { at first contact with the golf ball }\end{array}$ & \pm 1.5 & $\begin{array}{l}\text { The velocity the clubhead travels meas- } \\
\text { ured just prior to ball contact. }\end{array}$ & \pm 0.75 \\
\hline & Attack Angle ${ }^{3}$ & $\underline{0}$ & $\begin{array}{l}\text { Angle between the final point of a second order polynomial } \\
\text { curve fitted through the XZ coordinates of the clubhead } \\
\mathrm{COG}^{2} \text { and the XY plane, therefore this represented attack } \\
\text { angle projected onto the XZ plane. A negative angle meant a } \\
\text { descending clubhead COG. }\end{array}$ & $\begin{array}{l}\text { The vertical direction of the clubhead's centre of } \\
\text { gravity movement at maximum compression of the } \\
\text { golf ball. }\end{array}$ & \pm 1.0 & $\begin{array}{l}\text { The descending or ascending path of the } \\
\text { clubhead. }\end{array}$ & \pm 0.5 \\
\hline & Club Direction ${ }^{3}$ & $\underline{0}$ & $\begin{array}{l}\text { Angle between the final point of a second order polynomial } \\
\text { curve fitted through the XY coordinates of the clubhead } \\
\mathrm{COG}^{2} \text { and the XZ plane, therefore this represented the club } \\
\text { direction projected onto the XY plane. A positive value } \\
\text { meant a club direction moving to the right of the target line, } \\
\text { an in-to-out path for a right-handed golfer. }\end{array}$ & $\begin{array}{l}\text { The horizontal direction of the clubhead's centre of } \\
\text { gravity movement at maximum compression of the } \\
\text { golf. }\end{array}$ & \pm 1.0 & $\begin{array}{l}\text { The swing path measured in a horizontal } \\
\text { plane relative to target-line. }\end{array}$ & \pm 0.5 \\
\hline & $\begin{array}{c}\text { Face Angle } \\
{\text { (Impact Location })^{4}} \\
\text { Face Angle } \\
{\text { (Geometric Centre })^{4}}^{\text {(Geom }}\end{array}$ & $\underline{\mathrm{o}}$ & $\begin{array}{l}\text { Angle between the normal to the clubface at the impact } \\
\text { location and the target vertical XZ plane. } \\
\text { Angle between the normal to the clubface at the geometric } \\
\text { club face centre and the target vertical XZ plane. }\end{array}$ & \multirow[t]{2}{*}{$\begin{array}{l}\text { The horizontal club face orientation at the centre- } \\
\text { point of contact between club face and golf ball at } \\
\text { the maximum compression of the golf ball. }\end{array}$} & \multirow[t]{2}{*}{ \pm 0.6} & \multirow[t]{2}{*}{$\begin{array}{l}\text { The dynamic measurement of the club- } \\
\text { head's face plane position at a right angle } \\
\text { 9o degrees perpendicular relative to the } \\
\text { target line. }\end{array}$} & \multirow[t]{2}{*}{ \pm 0.5} \\
\hline & & & $\begin{array}{l}\text { A positive value indicates an open face, pointing to the right } \\
\text { of the target line. }\end{array}$ & & & & \\
\hline & 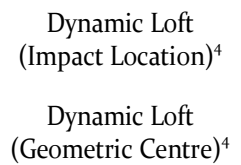 & $\underline{0}$ & $\begin{array}{l}\text { Angle between the normal to the clubface at the impact } \\
\text { location and the horizontal XY plane. } \\
\text { Angle between the normal to the clubface at the geometric } \\
\text { club face centre and the horizontal XY plane. }\end{array}$ & $\begin{array}{l}\text { The vertical club face orientation at the centre- } \\
\text { point of contact between the club face and golf ball } \\
\text { at the maximum compression of the golf ball. }\end{array}$ & \pm 0.8 & $\begin{array}{l}\text { The dynamic measurement in degrees of } \\
\text { the clubhead's face plane position verti- } \\
\text { cally relative to the ground plane. }\end{array}$ & \pm 0.75 \\
\hline
\end{tabular}




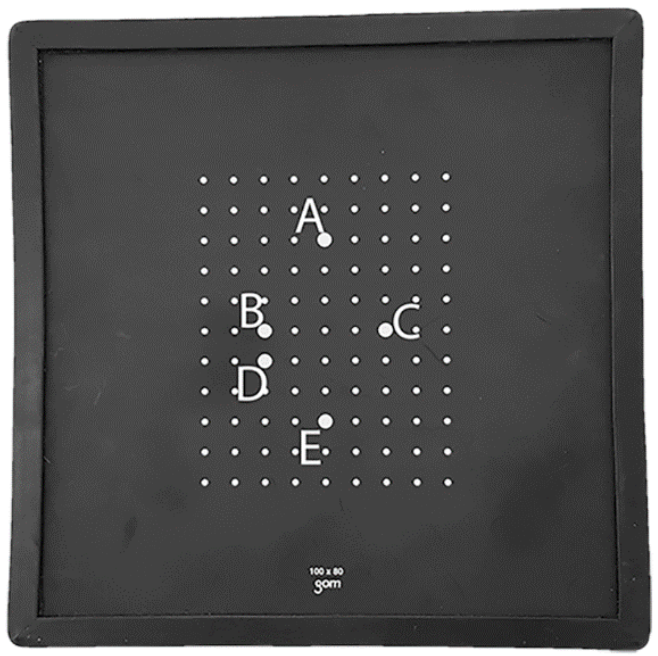

Figure 7: The GOM calibration board used for the point tracking accuracy investigation. The points used in this analysis are marked A - E.

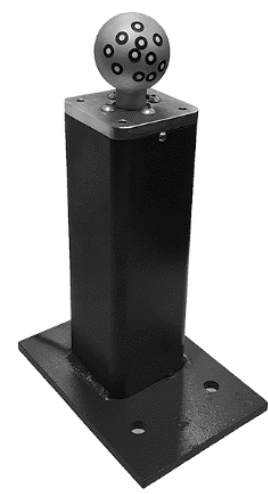

Figure 8: The custom-built, GOM markered spinning device used to assess the GOM spin rate calculations.

\section{Statistical Analysis}

Clubhead and ball parameters reported by TrackMan and Foresight were analysed independently against those obtained from the GOM system. For each trial and parameter, the GOM system measurement was subtracted from both TrackMan and Foresight values to generate difference data. Kolmogorov-Smirnov with Lilliefors correction checks were conducted to test for normality of the difference data. Data were analysed using non-parametric methods due to the frequency of non-normally distributed data sets. Median values along with interquartile ranges were therefore deemed the most suitable measures of central tendency and dispersion.

Non-parametric Wilcoxon signed rank tests were conducted to identify median differences that were significantly different to zero. Limits of Agreement analysis [16] was used to further investigate the agreement between each launch monitor and the benchmark GOM system using the first non-parametric method outlined by Bland and Altman [17]. Finally, two reference grades were de- fined, research and coaching, and the proportion of points that lay within the median plus or minus the reference value determined. Research grade was defined as the degree of agreement the authors considered necessary for the system to be used in scientific research. Coaching grade was the degree of agreement the authors considered suitable for a golf professional. In determining the reference ranges, consideration was given to the range of values typically encountered, the differences in values between each club and golfer as well as the sensitivity of shot outcomes to small changes in each parameter. Full analysis was done initially on a group (all clubs) comparison then broken down into a club-by-club analysis.

\section{Results \\ GOM system accuracy}

For point tracking, the systematic error (mean difference) between the GOM and SmartScope measurements was 3 microns (Table 2), therefore it was not deemed necessary to apply a correction factor to compensate for a systematic difference. The corresponding uncertainty in the measurement was found to be 64 microns (95\% confidence interval). From GOM tracking of the stationary ball centre position the uncertainty ( $95 \%$ confidence interval) ranged from 21 to 56 microns across the $\mathrm{x}, \mathrm{y}$ and $\mathrm{z}$ directions demonstrating good agreement with the SmartScope study data. Based on these results, Gaussian white noise with a standard deviation of 25 microns was added to the co-ordinates of each data point in the ball flight simulations. These subsequent simulations gave uncertainty values (95\% confidence intervals) of $0.06 \mathrm{mph}$ in ball velocity, $0.01^{\circ}$ in both launch angle and launch direction, and $14 \mathrm{rpm}$ in spin rate. In support of these simulation results, the experimental comparison of GOM to oscilloscope spin rate measurements gave a very similar uncertainty value of $9 \mathrm{rpm}$ (Table 3 ).

Table 2: Comparison of the measured distance between points from the GOM and SmartScope systems. Each value is the mean of five repeat measurements.

\begin{tabular}{|c|c|c|c|}
\hline Points & $\begin{array}{l}\text { SmartScope } \\
\text { distance } \\
(\mathrm{mm})\end{array}$ & $\begin{array}{l}\text { GOM } \\
\text { distance } \\
(\mathrm{mm})\end{array}$ & $\begin{array}{c}\text { Difference } \\
\text { (GOM - SmartScope) } \\
(\mathrm{mm})\end{array}$ \\
\hline $\mathrm{AC}$ & 36.0013 & 36.0222 & 0.0209 \\
\hline $\mathrm{AD}$ & 44.6700 & 44.6231 & -0.0469 \\
\hline $\mathrm{AE}$ & 59.9759 & $59 \cdot 9964$ & 0.0205 \\
\hline $\mathrm{BC}$ & 39.9302 & $39 \cdot 9440$ & 0.0138 \\
\hline $\mathrm{BD}$ & 10.0013 & 10.0034 & 0.0021 \\
\hline $\mathrm{BE}$ & 36.0221 & $35 \cdot 9547$ & -0.0674 \\
\hline $\mathrm{CE}$ & 36.0342 & 36.0521 & 0.0179 \\
\hline $\mathrm{CD}$ & 41.1515 & 41.1455 & -0.0060 \\
\hline $\mathrm{DE}$ & 28.2508 & 28.2697 & 0.0189 \\
\hline \multicolumn{3}{|c|}{ Mean Difference } & -0.0029 \\
\hline \multicolumn{3}{|c|}{$95 \%$ Confidence Interval } & 0.0636 \\
\hline & & Range & -0.0674 to 0.0209 \\
\hline
\end{tabular}


Table 3: Difference in spin rate of the spinning sphere measured by the GOM system compared to the oscilloscope.

\begin{tabular}{cc}
\hline $\begin{array}{c}\text { Nominal Spin Rate } \\
(\mathrm{rpm})\end{array}$ & $\begin{array}{c}\text { Difference } \\
(\mathrm{GOM}-\text { Oscilloscope }) \\
(\mathrm{rpm})\end{array}$ \\
\hline 3000 & 2 \\
3500 & 0 \\
4000 & 2 \\
4500 & 3 \\
5000 & 0 \\
5500 & -2 \\
6000 & 4 \\
6500 & -5 \\
7000 & 1 \\
7500 & -4 \\
8000 & -9 \\
8500 & -2 \\
9000 & -6 \\
9500 & -12 \\
\hline Mean Difference & -2 \\
$95 \%$ Confidence Intervals & 9 \\
Range & -12 to 4 \\
\hline
\end{tabular}

\section{Launch monitor evaluation}

For the launch monitor validation analysis a total of 240 trials were collected across all golfers and clubs. Foresight successfully tracked the ball and clubhead in $90 \%$ and $75 \%$ of trials respectively. TrackMan tracked the ball in $98 \%$ of trials, while the clubhead velocity was tracked in $98 \%$ of shots with the remaining clubhead parameters were tracked in $62 \%$ of shots. Notably, TrackMan only tracked attack angle, club direction, face angle and dynamic loft in $19 \%$ of shots for the utility wedge. Consequently, individual club analysis of the TrackMan clubhead parameters for the utility wedge, except clubhead velocity, were excluded; although this data remained in the combined clubs analysis.

Overall median differences and upper and lower quartiles for both TrackMan and Foresight for each impact parameter are shown in Figures 9 and 10 and Table 4; the same data but broken down by club are shown in Table 5 . Median differences provide an indication of systematic bias whilst interquartile ranges are a measure of random variability in the data. Finally, the percentage of measured values that satisfied the defined research and coaching grades are presented for each launch monitor in Table 6 .

It can be seen from Tables 4 and 5 that many of the median differences emerged as statistically significant but often the differences are negligible from a practical perspective. Only those parameters with a larger median difference, typically indicated by an interquartile range that doesn't span zero, received attention as these instances are more likely to have practical significance.

Ball velocity was measured very well by both launch monitors across all clubs. Systematic bias was negligible from a practical perspective and over $80 \%$ of measurements met the research grade $( \pm 1 \mathrm{mph})$ indicating strong agreement with the GOM data.

Ball path, as described by launch angle and direction, was also generally measured well across all clubs, with over $70 \%$ of measurements satisfying the research grade $\left( \pm 1^{\circ}\right)$. Launch angle was measured particularly well by Foresight with an interquartile range of just $0.3^{\circ}$. For both launch monitors, there was more variability in the launch direction measurements compared to launch angle. There was also notable systematic bias of $1-2^{\circ}$ in the launch direction measurements from Foresight.

Less variability was observed in the TrackMan spin rates compared to Foresight, with over $80 \%$ of values falling within \pm 50 rpm of the median value measured. Larger variability in the Foresight spin rate data from the lower spinning driver shots has compounded this observation. There was, however, greater systematic bias in the TrackMan data, with this launch monitor typically underestimating spin rates by $\sim 50 \mathrm{rpm}$ across all clubs with a number of notable extreme outliers also present (Figure 9).

Compared to ball parameters, weaker agreement was found for almost all clubhead parameters and this trend was consistent across both launch monitors. Greater variability in the clubhead velocity measurements resulted in only $54 \%$ of TrackMan values and just $29 \%$ of Foresight values satisfying the research grade of $\pm 1 \mathrm{mph}$. Both launch monitors performed better when considered against the coaching grade of $\pm 2.5 \mathrm{mph}$. Significant systematic bias was evident for both; TrackMan tended to underestimate clubhead velocity (by $\sim 1 \mathrm{mph}$ ) when compared to the clubhead COG velocity determined by GOM, whereas Foresight tended to overestimate clubhead velocity (by 2-4 mph), particularly for the driver.

Measurements of clubhead path were in closer agreement for the Foresight data with over $58 \%$ of attack angle and club direction values satisfying the research grade $\left( \pm 1^{\circ}\right)$. The majority of Foresight data that fell outside of this range is likely to have been from driver shots due to the increased interquartile range for this club. TrackMan on the other hand tended to underestimate attack angle particularly with the driver $\left(-3.5^{\circ}\right)$ when compared to the 7-Iron $\left(-0.6^{\circ}\right)$.

In contrast to the clubhead path results, measurements of clubhead orientation were in closer agreement for the TrackMan data with over $65 \%$ of face angle and dynamic loft values satisfying the research grade $\left( \pm 1^{\circ}\right)$. Even when compared to the coaching grade, Foresight struggled particularly with face angle, resulting in an overall interquartile range of nearly $5^{\circ}$. Significant systematic bias was also evident in the dynamic loft values from both launch monitors, with TrackMan typically underestimating by $\sim 1^{\circ}$ and Foresight overestimating by $1-2^{\circ}$ for the irons but by as much as $5^{\circ}$ for the driver. 

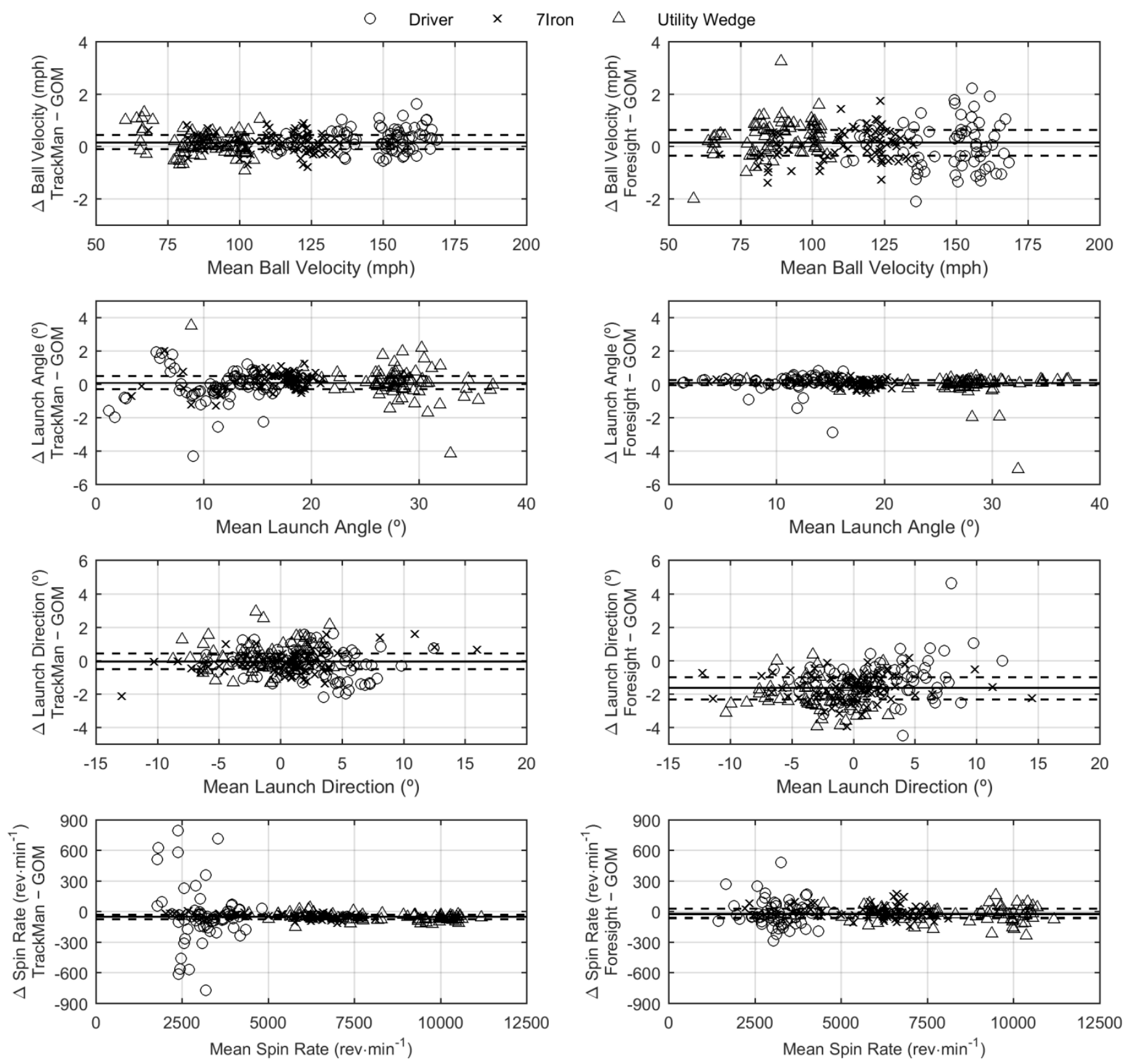

Figure 9: Bland-Altman plots for each ball parameter. The solid horizontal line represents the median difference and the dashed horizontal lines the lower and upper quartile differences.

\section{Discussion}

The purpose of this study was to investigate the degree of agreement in golf impact parameter outputs from two commercially available launch monitors, TrackMan Pro IIIe and Foresight GC2+HMT, compared to measurements taken using the benchmark GOM Inspect optical motion tracking system. As a preliminary step, the accuracy of the GOM system was assessed. Comparisons were then made for key clubhead and ball parameters through Limits of Agreement analysis. It was hypothesised that clubhead and ball velocities and trajectories from both launch monitors would show close agreement with the GOM system, but there would be poorer agreement for clubhead orientations and ball spin rate.
The GOM system was chosen as the comparison benchmark because of its reported point tracking accuracy of 25 microns per metre field of view (personal communication with the manufacturer). However, overall point tracking accuracy is dependent on the specifics of the hardware set-up; therefore, a preliminary analysis of the GOM system accuracy applicable to this study was required. The results of this preliminary analysis gave a point tracking systematic error of 3 microns and uncertainty (95\% confidence interval) of 64 microns, values similar in magnitude to those reported in previous literature [18]. This was estimated to translate into uncertainties of $0.06 \mathrm{mph}$ in ball velocity, $0.01^{\circ}$ in launch angle and launch direction, and $14 \mathrm{rpm}$ in spin rate. 

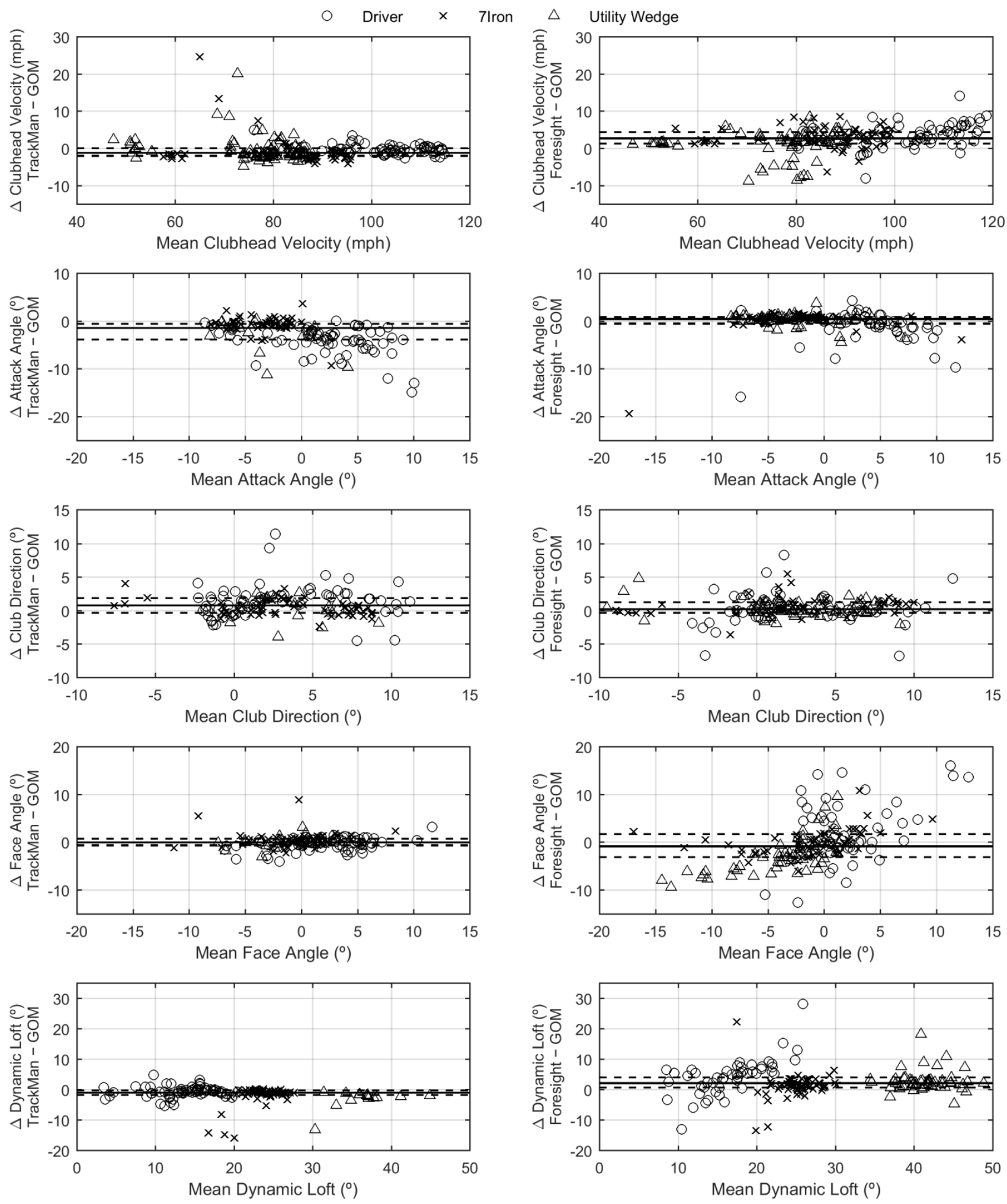

Figure 10: Bland-Altman plots for each club parameter. The solid horizontal line represents the median difference and the dashed horizontal lines the lower and upper quartile differences. 
Table 4: Median differences and interquartile ranges for $\mathrm{T}$ (TrackMan minus GOM) and F (Foresight minus GOM) for all parameters.

\begin{tabular}{|c|c|c|c|c|c|}
\hline & Variable & Launch monitor & Median difference & Lower quartile & Upper quartile \\
\hline Ball & Ball velocity & $\mathrm{T}$ & $0.2^{*}$ & -0.1 & 0.5 \\
\hline \multirow[t]{7}{*}{ Parameters } & $(\mathrm{mph})$ & $\mathrm{F}$ & $0.2^{*}$ & -0.3 & 0.6 \\
\hline & Launch angle & $\mathrm{T}$ & $0.1^{*}$ & -0.3 & 0.5 \\
\hline & (o) & $\mathrm{F}$ & $0.1^{*}$ & 0.0 & 0.3 \\
\hline & Launch direction & $\mathrm{T}$ & 0.0 & -0.5 & 0.5 \\
\hline & (o) & $\mathrm{F}$ & $-1.6^{*}$ & -2.3 & -1.0 \\
\hline & Total spin & $\mathrm{T}$ & $-47^{*}$ & -73 & -26 \\
\hline & (rpm) & $\mathrm{F}$ & $-20^{*}$ & $-6 o$ & 30 \\
\hline Club & Clubhead velocity & $\mathrm{T}$ & $-1.1^{*}$ & -1.9 & 0.1 \\
\hline \multirow[t]{9}{*}{ Parameters } & (mph) & $\mathrm{F}$ & $2.8^{*}$ & 1.4 & $4 \cdot 5$ \\
\hline & Attack angle & $\mathrm{T}$ & $-1.4^{*}$ & $-3 \cdot 7$ & -0.5 \\
\hline & $(\stackrel{o}{)})$ & $\mathrm{F}$ & $0.5^{*}$ & -0.3 & 1.0 \\
\hline & Club direction & $\mathrm{T}$ & $0.8^{*}$ & -0.3 & 1.9 \\
\hline & (o) & $\mathrm{F}$ & $0.2^{*}$ & -0.3 & 1.3 \\
\hline & Face angle & $\mathrm{T}$ & o.o & -0.6 & 0.8 \\
\hline & (o) & $\mathrm{F}$ & -0.8 & -3.0 & 1.8 \\
\hline & Dynamic loft & $\mathrm{T}$ & $-0.9^{*}$ & -1.7 & -0.2 \\
\hline & (o) & $\mathrm{F}$ & $2.2^{*}$ & 0.8 & 4.0 \\
\hline
\end{tabular}

\section{×Significant $(\mathrm{p}<0.05)$}

The simulation approach couldn't be applied to the clubhead data in the same way as the ball due to subtle differences in the calculation procedure but it is anticipated that the uncertainties in clubhead parameters would be of a similar magnitude. Thus, the GOM system appeared to be an appropriate benchmark system for the intended launch monitor evaluation investigation, with greater measurement accuracies for ball and clubhead parameters than both TrackMan and Foresight.

Contrary to the hypothesis, the clearest distinction in the data was between clubhead and ball parameters. Both launch monitors measured ball parameters better than clubhead parameters as evidenced by fewer systematic biases, smaller interquartile ranges and a greater proportion of the data satisfying the research grade specified. This trend may be a legacy of the development process as early versions of each launch monitor only reported ball parameters and clubhead measurement was introduced at a later data

Weaker agreement was found when clubhead velocity measured by both launch monitors was compared to the GOM measurements; greater systematic bias and random variability was present in the data, particularly when considered relative to the ball velocity data. Immediately before impact, the clubhead is both translating and rotating and, as a result, velocity can vary by as much as $12.8 \mathrm{mph}$ from heel to toe across a driver clubface [7]. Differences are, therefore, to be expected depending on where on the clubhead the velocity measurement is taken. The velocity of the clubhead COG was considered the most appropriate measure of clubhead speed and was calculated using the GOM system based on location data provided by the manufacturer. COG location, however, is specific to each clubhead and without this information, neither Foresight nor TrackMan can measure the velocity of the COG directly, regardless of their definitions. Instead, velocity of a point on the surface of the clubhead is measured and this may account for discrepancies in the data

Clubhead orientation parameters can change rapidly leading up to impact due to clubhead rotations primarily about the shaft axis. The face angle of a driver closes at a rate of $2.9^{\circ} / \mathrm{ms}$ immediately prior to impact [7]. Therefore, the point in time at which the measurement is taken will significantly affect the output from the launch monitors. Timing is therefore critical especially when it is considered that a $2^{\circ}$ difference in face angle corresponds to 10 $\mathrm{m}$ in lateral dispersion of a $280 \mathrm{~m}$ drive [4]. Poor agreement was found between the face angle data obtained from Foresight and GOM and it may be that differences in the timing of the measurement contributed to this. TrackMan, in comparison, doesn't directly measure clubhead orientation parameters but calculates them from an impact model using other parameters; it is interesting to note that it appears to achieve more reliable results using this approach.

Prior to impact, the clubhead COG travels along an arc and the curvature of the path makes attack angle and club direction hard to define. The rate of change of these parameters is significantly less than the rate of change in face angle [19], but again differences in the timing of when measurements are taken could contribute to variability in the data. 
Table 5: Median differences and interquartile ranges for $T$ (TrackMan minus GOM) and $F$ (Foresight minus GOM) for all parameters on a club-by-club basis.

\begin{tabular}{|c|c|c|c|c|c|c|}
\hline & Variable & $\begin{array}{l}\text { Launch } \\
\text { monitor }\end{array}$ & Median difference & Lower quartile & Upper quartile & GOM Mean \\
\hline \multirow{18}{*}{ Driver } & \multirow{2}{*}{$\begin{array}{l}\text { Ball velocity } \\
\text { (mph) }\end{array}$} & $\mathrm{T}$ & $0.2^{*}$ & 0.0 & 0.6 & \multirow{2}{*}{146.2} \\
\hline & & $\mathrm{F}$ & 0.0 & -0.6 & 0.6 & \\
\hline & Launch angle & $\mathrm{T}$ & 0.0 & -0.4 & 0.4 & \multirow{2}{*}{11.2} \\
\hline & $($ o) & $\mathrm{F}$ & $0.3^{*}$ & 0.1 & 0.4 & \\
\hline & Launch direction & $\mathrm{T}$ & 0.0 & -0.9 & 0.5 & \multirow{2}{*}{2.3} \\
\hline & $(\stackrel{o}{)})$ & $\mathrm{F}$ & $-1.1^{*}$ & -1.7 & -0.5 & \\
\hline & Total spin & $\mathrm{T}$ & $-63^{*}$ & -110 & -18 & \multirow{2}{*}{3140} \\
\hline & $(\mathrm{rpm})$ & $\mathrm{F}$ & -31 & -92 & 50 & \\
\hline & Clubhead velocity & $\mathrm{T}$ & $-0.4^{*}$ & -1.2 & 0.3 & \multirow{2}{*}{100.8} \\
\hline & (mph) & $\mathrm{F}$ & $3 \cdot 9^{*}$ & 1.6 & 5.9 & \\
\hline & Attack angle & $\mathrm{T}$ & $-3 \cdot 5^{*}$ & $-4 \cdot 5$ & -2.0 & \multirow{2}{*}{$3 \cdot 9$} \\
\hline & $(\underline{o})$ & $\mathrm{F}$ & -0.3 & -1.4 & 0.7 & \\
\hline & Club direction & $\mathrm{T}$ & $1.5^{*}$ & 0.3 & 2.4 & \multirow{2}{*}{1.9} \\
\hline & $(\underline{o})$ & $\mathrm{F}$ & 0.1 & -0.8 & 1.5 & \\
\hline & Face angle & $\mathrm{T}$ & -0.1 & -0.9 & 0.6 & 2.1 \\
\hline & $(\stackrel{o}{)})$ & $\mathrm{F}$ & $0.8^{*}$ & -1.1 & 5.8 & 0.8 \\
\hline & Dynamic loft & $\mathrm{T}$ & $-0.5^{*}$ & -1.1 & 0.1 & 13.7 \\
\hline & $(\mathrm{o})$ & $\mathrm{F}$ & $5.2^{*}$ & 1.3 & 7.0 & 14.0 \\
\hline \multirow{18}{*}{ 7-Iron } & Ball velocity & $\mathrm{T}$ & $0.2^{*}$ & -0.1 & 0.4 & \multirow{2}{*}{111.5} \\
\hline & (mph) & $\mathrm{F}$ & 0.1 & -0.3 & 0.5 & \\
\hline & Launch angle & $\mathrm{T}$ & $0.3^{*}$ & 0.0 & 0.6 & \multirow{2}{*}{16.7} \\
\hline & $(\underline{o})$ & $\mathrm{F}$ & $0.1^{*}$ & 0.0 & 0.2 & \\
\hline & Launch direction & $\mathrm{T}$ & -0.1 & -0.5 & 0.4 & \multirow[b]{2}{*}{0.5} \\
\hline & $(\underline{\mathrm{o}})$ & $\mathrm{F}$ & $-1.6^{*}$ & -2.2 & -1.0 & \\
\hline & Total spin & $\mathrm{T}$ & $-44^{*}$ & -55 & -28 & \multirow{2}{*}{5916} \\
\hline & $(\mathrm{rpm})$ & $\mathrm{F}$ & -8 & -43 & 29 & \\
\hline & Clubhead velocity & $\mathrm{T}$ & $-1.6^{*}$ & -2.4 & -0.7 & \multirow{2}{*}{83.4} \\
\hline & (mph) & $\mathrm{F}$ & $2.7^{*}$ & 1.8 & $4 \cdot 4$ & \\
\hline & Attack angle & $\mathrm{T}$ & $-0.6^{*}$ & -1.1 & 0.1 & \multirow{2}{*}{-3.0} \\
\hline & $(\underline{o})$ & $\mathrm{F}$ & $0.7^{*}$ & 0.4 & 1.0 & \\
\hline & Club direction & $\mathrm{T}$ & $0.4^{*}$ & -0.5 & 1.1 & \multirow{2}{*}{2.1} \\
\hline & $(\underline{o})$ & $\mathrm{F}$ & $0.5^{*}$ & -0.1 & 1.2 & \\
\hline & Face angle & $\mathrm{T}$ & $-0.4^{*}$ & -0.4 & 1.0 & \multirow{2}{*}{-1.3} \\
\hline & $(\underline{o})$ & $\mathrm{F}$ & -0.3 & -2.1 & 1.7 & \\
\hline & Dynamic loft & $\mathrm{T}$ & $-0.9^{*}$ & -1.4 & -0.2 & 24.2 \\
\hline & $(\underline{o})$ & $\mathrm{F}$ & $1.6^{*}$ & 0.2 & 2.5 & 24.2 \\
\hline Wedoe & Ball velocity & $\mathrm{T}$ & $0.1^{*}$ & -0.1 & 0.4 & 887 \\
\hline veage & (mph) & $\mathrm{F}$ & $0.4^{*}$ & -0.1 & 0.8 & 88.1 \\
\hline & Launch angle & $\mathrm{T}$ & $0.1^{*}$ & -0.2 & 0.6 & 278 \\
\hline & $(\underline{o})$ & $\mathrm{F}$ & $0.1^{*}$ & -0.1 & 0.2 & 27.0 \\
\hline & Launch direction & $\mathrm{T}$ & $0.2^{*}$ & -0.3 & 0.8 & \\
\hline & $(\underline{o})$ & $\mathrm{F}$ & $-2.1^{*}$ & -2.6 & -1.6 & -1.1 \\
\hline & Total spin & $\mathrm{T}$ & $-56^{*}$ & -74 & -37 & 8571 \\
\hline & (rpm) & $\mathrm{F}$ & $-21^{*}$ & -74 & 17 & \\
\hline & Clubhead velocity & $\mathrm{T}$ & $-1.3^{*}$ & -2.0 & 0.6 & \\
\hline & $(\mathrm{mph})$ & $\mathrm{F}$ & $1.7^{*}$ & 0.9 & $3 \cdot 4$ & 76.5 \\
\hline & Attack angle & $\mathrm{T}$ & - & - & - & \\
\hline & $(\underline{o})$ & $\mathrm{F}$ & $0.5^{*}$ & 0.1 & 1.0 & $-3 \cdot 4$ \\
\hline & Club direction & $\mathrm{T}$ & - & - & - & 8 \\
\hline & $(\stackrel{o}{)})$ & $\mathrm{F}$ & 0.1 & -0.4 & 0.9 & 1.8 \\
\hline & Face angle & $\mathrm{T}$ & - & - & - & -26 \\
\hline & $(\underline{o})$ & $\mathrm{F}$ & $-3.1^{*}$ & $-5 \cdot 7$ & -0.9 & -2.0 \\
\hline & Dynamic loft & $\mathrm{T}$ & - & - & - & \\
\hline & $(\underline{o})$ & $\mathrm{F}$ & $2.2^{*}$ & 1.1 & 3.1 & 40.3 \\
\hline
\end{tabular}


Table 6: The percentage of data points within the research grade and coaching grade reference ranges for each parameter and launch monitor.

\begin{tabular}{|c|c|c|c|c|}
\hline & Parameter & $\begin{array}{l}\text { Reference } \\
\text { range }\end{array}$ & $\begin{array}{c}\text { TrackMan } \\
\text { (\%) }\end{array}$ & $\begin{array}{c}\text { Foresight } \\
(\%)\end{array}$ \\
\hline \multirow[t]{9}{*}{$\begin{array}{l}\text { Research } \\
\text { Grade }\end{array}$} & $\begin{array}{c}\text { Ball } \\
\text { Velocity }\end{array}$ & $\pm 1 \mathrm{mph}$ & 98 & 84 \\
\hline & $\begin{array}{l}\text { Launch } \\
\text { Angle }\end{array}$ & $\pm 1^{\mathrm{o}}$ & 87 & 97 \\
\hline & $\begin{array}{l}\text { Launch } \\
\text { Direction }\end{array}$ & $\pm 1^{\mathrm{o}}$ & 76 & 71 \\
\hline & Spin Rate & $\pm 50 \mathrm{rpm}$ & 83 & 54 \\
\hline & $\begin{array}{l}\text { Clubhead } \\
\text { Velocity }\end{array}$ & $\pm 1 \mathrm{mph}$ & 54 & 29 \\
\hline & $\begin{array}{l}\text { Attack } \\
\text { Angle }\end{array}$ & $\pm 1^{\mathrm{o}}$ & 38 & 67 \\
\hline & $\begin{array}{c}\text { Club } \\
\text { Direction }\end{array}$ & $\pm 1^{0}$ & 45 & 58 \\
\hline & $\begin{array}{c}\text { Face } \\
\text { Angle }\end{array}$ & $\pm 1^{\circ}$ & 66 & 26 \\
\hline & $\begin{array}{l}\text { Dynamic } \\
\text { Loft }\end{array}$ & $\pm 1^{\mathbf{o}}$ & 65 & 33 \\
\hline \multirow[t]{9}{*}{$\begin{array}{l}\text { Coaching } \\
\text { Grade }\end{array}$} & $\begin{array}{c}\text { Ball } \\
\text { Velocity }\end{array}$ & $\pm 2.5 \mathrm{mph}$ & 100 & 99 \\
\hline & $\begin{array}{l}\text { Launch } \\
\text { Angle }\end{array}$ & $\pm 2^{\circ}$ & 97 & 98 \\
\hline & $\begin{array}{l}\text { Launch } \\
\text { Direction }\end{array}$ & $\pm 2^{\circ}$ & 98 & 95 \\
\hline & Spin Rate & $\pm 150 \mathrm{rpm}$ & 97 & 91 \\
\hline & $\begin{array}{l}\text { Clubhead } \\
\text { Velocity }\end{array}$ & $\pm 2.5 \mathrm{mph}$ & 87 & 67 \\
\hline & $\begin{array}{l}\text { Attack } \\
\text { Angle }\end{array}$ & $\pm 2^{\circ}$ & 65 & 83 \\
\hline & $\begin{array}{c}\text { Club } \\
\text { Direction }\end{array}$ & $\pm 2^{\circ}$ & 82 & 86 \\
\hline & $\begin{array}{l}\text { Face } \\
\text { Angle }\end{array}$ & $\pm 2^{\circ}$ & 89 & 46 \\
\hline & $\begin{array}{c}\text { Dynamic } \\
\text { Loft }\end{array}$ & $\pm 2^{\circ}$ & 83 & 59 \\
\hline
\end{tabular}

The two launch monitors used in this study take a very different approach to alignment. TrackMan has selflevelling legs and a built-in video camera which enables a target line to be selected. Foresight needs to be placed in a specific region relative to the ball but has no formal means of target line alignment, although it does have an accelerometer for self-levelling. Whilst care was taken to align all three measurement systems relative to each other and the target line, small discrepancies are inevitable. This may have contributed to the systematic bias in the Foresight launch direction data; a similar offset, however, was not observed in other data measured relative to the same target line (e.g. face angle and club direction), alt- hough it should also be noted that ball and clubhead parameters are measured by different units bolted together. Errors in dynamic loft, are unlikely to be due to alignment issues, as Foresight was placed and self-levelled on a level laboratory floor and no such issues were observed in related measurements such as launch angle.

Data collected from radar systems, such as TrackMan, contain information on the motion of every moving object within their field of view. As a result, the motion of the clubhead has to be distinguished from the motion of the ball. At impact their paths coincide and separating club data from ball data becomes increasingly difficult as the difference in their respective velocities reduces. For the utility wedge, ball velocity is more similar to clubhead velocity than it is with a driver and this is a possible cause of the poor success rate in measuring clubhead parameters for this club. In the region of impact, both clubhead and ball are travelling close to the ground and a radar system will not only receive a signal reflected directly back from each moving object but will also receive a signal reflected back via the ground. Again, this will add noise to the data, which may have contributed to less than $50 \%$ of TrackMan measurements of clubhead path (attack angle and clubhead direction) satisfying the research grade.

It was considered important to collect data from all three systems simultaneously for direct comparison of results from each shot. A consequence of this approach, however, is the potential for interference between systems. The presence of large metallic tripods and lights close to the tee may have affected the quality of the radar data. The high intensity lighting required for the high speed cameras could have affected the quality of Foresight images. Markers placed on both the clubhead and ball for the GOM system in addition to the metallic dot on the ball for TrackMan, may have affected the Foresight algorithms, although the GOM markers are not retroreflective. Compromises had to be made in marker placement and light intensity to find a balance where all systems appeared to function together effectively. This may be a reason for a lower percentage of shots tracked and, therefore, the data collected cannot be considered as originating from an optimal setup.

A challenging aspect of this study has been to measure equivalent parameters so that a like-for-like comparison can be made. There are no standardised definitions for any of the parameters and each launch monitor defines them in a different way. TrackMan, for example, reports face angle and dynamic loft at the location of impact on the face, whereas the Foresight definition is less clear. Consequently, two different face angles were generated from the GOM data but it had to be assumed that the angle of the centre of the face was the most appropriate for comparison with the Foresight data. TrackMan also specifies that a number of parameters are measured 'at maximum compression of the golf ball', whereas most launch monitors tend to report these values at the instant of ball contact. It is not clear how TrackMan determines the point of maximum ball compression, nor how this point would be identified in the GOM data, and so GOM 
measurements were determined at ball contact. The earlier discussion has illustrated how differences in the timing of a measurement can lead to discrepancies in the data.

From a practical perspective, the results suggest that the ball parameters measured by both launch monitors would be suitable for use in golf research; caution however, would need to be exercised in the use of clubhead parameters. For coaches and clubfitters, the parameters measured are largely of sufficient quality for their needs, although they should be watchful for occasional erroneous measurements. Perhaps of more concern for a coach, is the lack of a target-line alignment method for the Foresight; the resultant difficulty in positioning the unit parallel to the target line is likely to lead to greater errors in the parameters than those reported in this paper.

There are a number of avenues for further investigation. This study only considered a single clubhead of each type and differences in clubhead geometry may influence the measurements. For example, the TrackMan attack angle offset for the driver was potentially the result of the clubhead geometry. The testing was carried out indoors in a laboratory environment as this is often where biomechanical research is conducted. TrackMan is capable of tracking the whole ball flight and it is possible that the quality of ball parameters would improve further if more of the ball's trajectory was measured. Foresight requires markers to be attached to the clubface and their guidance was followed in the positioning of these markers. It was beyond the scope of this study however, to investigate the sensitivity of clubhead parameters to small changes in marker position. Finally, both launch monitors provide more parameters than have been reported in this paper, and these could be considered further.

\section{Conclusion}

This study has successfully compared the clubhead and ball impact parameters across three clubs for eight golfers as measured by the GOM optical system and the two launch monitors TrackMan Pro IIIe and Foresight GC2+HMT. In addition, the accuracy of the GOM system in this application set-up was demonstrated to be sufficient for its use as the benchmark system. The results demonstrated that the degree of agreement was noticeably stronger for ball parameters, with greater variability in the clubhead parameters. Strength of agreement also varied between clubs. Dependent on the launch monitor, parameters such as spin rate, club direction, attack angle and dynamic loft showed closer agreement with the GOM values for the 7-iron and wedge compared to the driver.

Launch monitors have many advantages including their instantaneous feedback and ease of set-up. For the scientific researcher, a high-level of confidence can be had in the ball parameters measured by both Trackman and Foresight; however, caution needs to be exercised in the use of clubhead parameters. Coaches, golfers and clubfitters should find the data to be of sufficient quality for most of their needs.

\section{References}

1. Ball, K.A. \& Best, R.J., (2007). Different centre of pressure patterns within the golf stroke I: Cluster analysis. Journal of Sports Sciences, 25(7), 757-70.

2. Tucker, C.B., Anderson, R. \& Kenny, I.C. (2013). Is outcome related to movement variability in golf? Sports Biomechanics, 1-12.

3. Williams, K.R. \& Sih, B.L. (2002). Changes in golf clubface orientation following impact with the ball. Sports Engineering, 5(2), 65-80.

4. Sweeney, M. et al. (2013). The influence of club-head kinematics on early ball flight characteristics in the golf drive. Sports Biomechanics, 12(3), 247-258.

5. Betzler, N.F. et al., (2014). The relationships between driver clubhead presentation characteristics, ball launch conditions and golf shot outcomes. Journal of Sports Engineering and Technology, 228(4), 242-249.

6. GOM. (2015). Available From: $<$ http://www.gom.com/metrology-systems/3d-motionanalysis.html>. [14 January 2016].

7. Ellis, K.L., Roberts, J.R. \& Sanghera, J. (2010). Development of a method for monitoring clubhead path and orientation through impact. Procedia Engineering, 2(2), 2955-2960.

8. TrackMan. (2014). TrackMan IIIe Operator Training Guide.

9. Foresight Sports. (2012a). GC2 User Manual.

10. Foresight Sports. (2012b). HMT Quickstart Manual.

11. Soderkvist, I. \& Wedin, P. (1993). Determining the movements of the skeleton using well-configured markers. Journal of Biomechanics, 26(12), 1473-1477.

12. Challis, J.H. (1995). A procedure for determining rigid body transformation parameters. Journal of Biomechanics, 28(6), 733-737.

13. Robertson, G. et al. (2013). Research Methods In Biomechanics IIE., Human Kinetics.

14. TrackMan. (2015). Available From: <http://blog.trackmangolf.com/category/golf/trackmanuniversity/definitions/page/2/>. [14 January 2016].

15. Foresight Sports. (2013). An introduction to understanding ball launch and club data.

16. Bland, J.M. \& Altman, D.G. (1986). Statistical methods for assessing agreement between two methods of clinical measurement. Lancet, 307-310.

17. Bland, J.M. \& Altman, D.G. (1999). Measuring agreement in method comparison studies. Statistical methods in medical research, 8(2), 135-160.

18. Doebele, S. et al., (2012). New method for detection of complex $3 \mathrm{D}$ fracture motion - Verification of an optical motion analysis system for biomechanical studies. BMC Musculoskeletal Disorders, 13(1), p.33-41.

19. Betzler, N.F. et al., (2012). Variability in clubhead presentation characteristics and ball impact location for golfers' drives. Journal of Sports Sciences, 30(5), 439-48. 